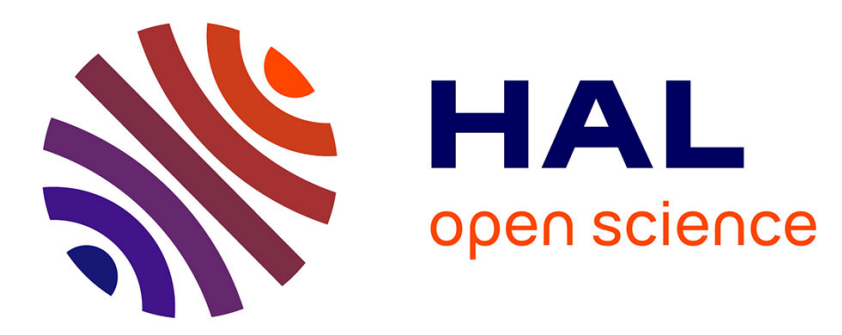

\title{
First-attempt success is associated with fewer complications related to intubation in the intensive care unit
}

Audrey de Jong, Amélie Rolle, Joris Pensier, Mathieu Capdevila, Samir Jaber

\section{- To cite this version:}

Audrey de Jong, Amélie Rolle, Joris Pensier, Mathieu Capdevila, Samir Jaber. First-attempt success is associated with fewer complications related to intubation in the intensive care unit. Intensive Care Medicine, 2020, 46, pp.1278-1280. 10.1007/s00134-020-06041-2 . hal-02553415

\author{
HAL Id: hal-02553415 \\ https://hal.science/hal-02553415
}

Submitted on 2 Jul 2020

HAL is a multi-disciplinary open access archive for the deposit and dissemination of scientific research documents, whether they are published or not. The documents may come from teaching and research institutions in France or abroad, or from public or private research centers.
L'archive ouverte pluridisciplinaire $\mathbf{H A L}$, est destinée au dépôt et à la diffusion de documents scientifiques de niveau recherche, publiés ou non, émanant des établissements d'enseignement et de recherche français ou étrangers, des laboratoires publics ou privés. 


\title{
First-attempt success is associated with fewer complications related to intubation in the intensive care unit
}

\author{
Audrey De Jong, Amélie Rolle, Joris Pensier, Mathieu Capdevila and Samir Jaber*
}

Dear Editor,

Patients admitted to intensive care units (ICUs) often require respiratory support. Tracheal intubation is one of the procedures performed most frequently in the ICU [1]. Tracheal intubation may be associated with moderate-to-severe complications, including hypoxemia, aspiration, dental injury, severe collapse, cardiac arrest and death $[1,2]$.

The association between the number of intubation attempts and the occurrence of complications remains poorly known in ICU patients. In a single-center study of 136 patients, Griesdale et al. [3] found that two or more attempts of intubation (first-attempt failure) were associated with an increased risk of severe complications. Other studies $[4,5]$ found that strictly having more than two attempts was associated with a significant increase in complications related to intubation. As the criterion "first-attempt intubation success" is increasingly selected to be a main endpoint in large randomized controlled trials, we aimed to determine whether first-attempt success in intubation is indeed associated with fewer intubationrelated complications than first-attempt failure. We made the hypothesis that first-attempt success would be associated with fewer complications than first-attempt failure.

The main endpoint was the incidence of complications related to intubation [4] in the hour following intubation (see supplemental content 1). Five databases coming from 64 ICUs including 1844 intubation procedures were retrospectively analyzed (see supplemental content 1 for

\footnotetext{
*Correspondence: s-jaber@chu-montpellier.fr

Intensive Care Unit and Transplantation, Department of Anesthesia and Critical Care B (DAR B), Hôpital Saint Eloi, CHU de Montpellier, PhyMedExp, Université de Montpellier, 80, Avenue Augustin Fliche, 34295 Montpellier Cedex 5, France
}

methodological details), and the data were adjusted for age, sex, reason for intubation, simplified acute physiologic score (SAPS) II, lowest peripheral oxygen saturation before intubation, lowest systolic blood pressure before intubation, hypnotic used for induction, use of neuromuscular blocking agent for induction, expert operator and anesthesiologist status.

Among the 1844 intubations available, there were $1440(78 \%)$ successful first attempts, 275 (15\%) successful second attempts, 88 (5\%) successful third attempts and $41(2 \%)$ of the intubations necessitated four or more attempts. The baseline characteristics of the study population are reported in supplemental content 1.

There were significantly fewer complications in the first-attempt success group compared to the first-attempt failure group [633/1440 (44\%) vs 243/404 (60\%); $p<0.001$, adjusted OR (odds ratio) 0.39 (95\% confidence interval (CI) 0.29-0.52)] There were fewer hypoxemias (Fig. 1a, adjusted OR $=0.29$ (95\% CI $0.21-0.40), p<0.001$ ), aspirations (Fig. 1c) and dental injuries (Fig. 1d) in the firstattempt success group compared to the first-attempt failure group. The incidence of hypoxemia (Fig. 1a), aspiration (Fig. 1c) and dental injury (Fig. 1d) increased with the increase in the number of attempts required for intubation. However, the likelihood of severe collapse was similar in the first-attempt success and first-attempt failure groups (Fig. 1b, adjusted OR 1.05 (95\% CI 0.77$1.45), p=0.75)$. We could speculate that repetitive laryngoscopies in the first-attempt failure group lead to more sympathetic adrenergic stimulation, thereby preventing vasoplegia and then occurrence of severe collapse (see supplemental content 1 ).

This is the first large, multicenter database retrospective analysis of complications related to intubation in 


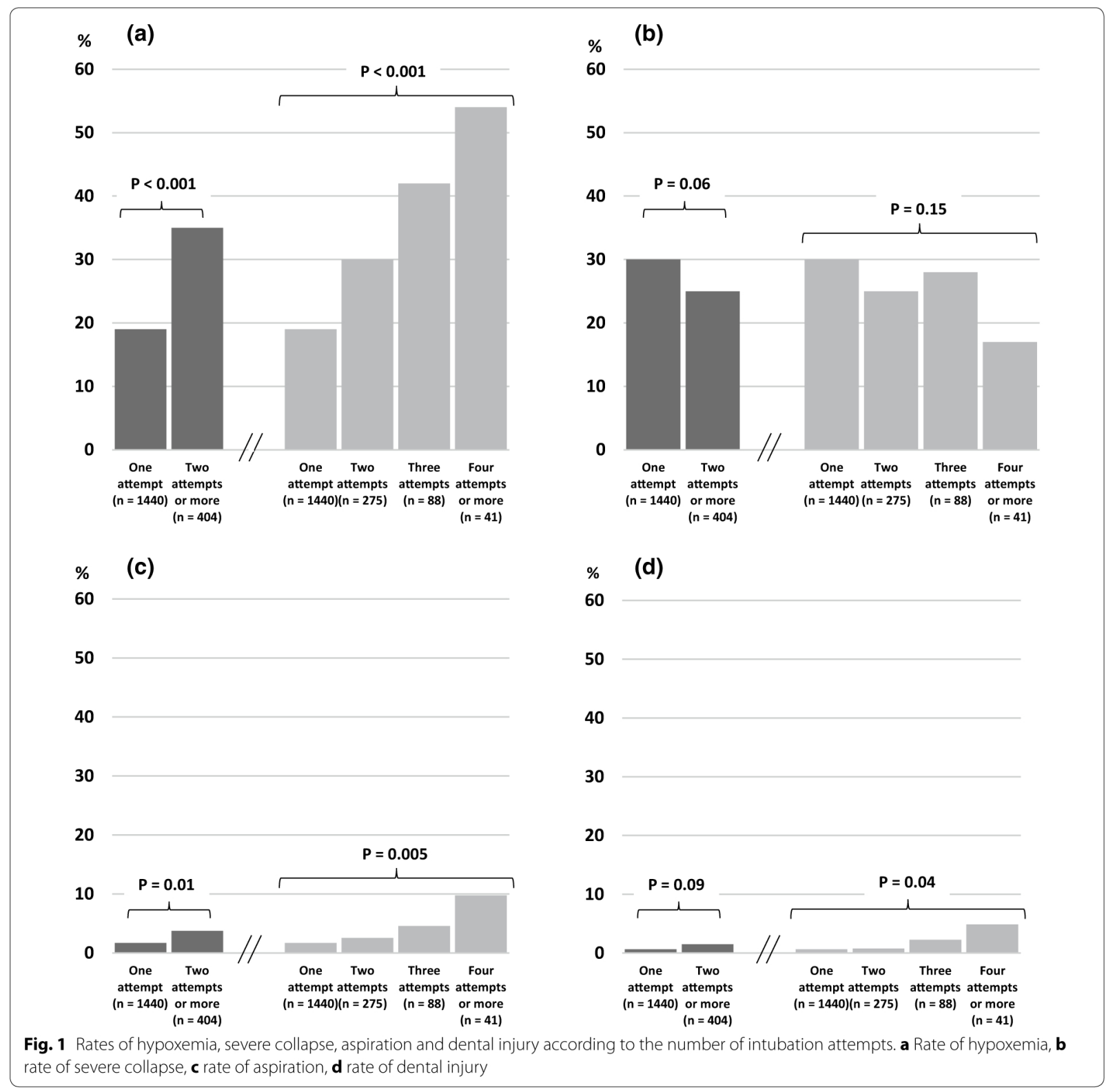

the ICU. We reported that the first-attempt success was associated with fewer complications related to intubation than the first-attempt failure. Despite the limitations of our study (see supplemental content 1 ), this finding validates that there is an urgent need to improve the rate of successful first intubation attempts in the ICU in order to decrease the rate of associated complications in these already critically ill patients.

\section{Compliance with ethical standards}

\section{Conflicts of interest}

Dr. Jaber reports receiving consulting fees from Drager, Medtronic, Baxter, Fresenius Medical and Fisher \& Paykel. No potential conflict of interest relevant to this article was reported for Dr. De Jong. 


\section{References}

1. Cook TM, Woodall N, Harper J, Benger J, on behalf of the Fourth National Audit Project (2011) Major complications of airway management in the UK: results of the Fourth National Audit Project of the Royal College of Anaesthetists and the Difficult Airway Society. Part 2: intensive care and emergency departments. Br J Anaesth 106:632-642

2. Quintard H, I'Her E, Pottecher J, Adnet F, Constantin JM, De Jong A, Diemunsch P, Fesseau R, Freynet A, Girault C, Guitton C, Hamonic Y, Maury E, Mekontso-Dessap A, Michel F, Nolent P, Perbet S, Prat G, Roquilly A, Tazarourte K, Terzi N, Thille AW, Alves M, Gayat E, Donetti L (2017) Intubation and extubation of the ICU patient. Anaesth Crit Care Pain Med $36: 327-341$
3. Griesdale DE, Bosma TL, Kurth T, Isac G, Chittock DR (2008) Complications of endotracheal intubation in the critically ill. Intensive Care Med 34:1835-1842

4. De Jong A, Molinari N, Terzi N, Mongardon N, Arnal JM, Guitton C, Allaouchiche B, Paugam-Burtz C, Constantin JM, Lefrant JY, Leone M, Papazian L, Asehnoune K, Maziers N, Azoulay E, Pradel G, Jung B, Jaber S (2013) Early identification of patients at risk for difficult intubation in the intensive care unit: development and validation of the MACOCHA score in a multicenter cohort study. Am J Respir Crit Care Med 187:832-839

5. Mort TC (2004) Emergency tracheal intubation: complications associated with repeated laryngoscopic attempts. Anesth Analg 99:607-613 